\title{
Türkiye'de Yetişen Withania Somnifera Dun. Bitkisinin Kimyasal Bileşimi
}

Constituents of Withania somnifera Dun. Growing in Turkey Erendiz ATASÜ*

GİRIS

Eski çağlardan beri Hint halk tıbbmda $W$ - somnifera Dun. (Solanaceae) bitkisinin yaprak ekstreleri antitumoral bir ajan olarak kullamlagelmiştir(1). Bitkiden 1967 'de Vitaferin A (Withaferin A) (2), ve 1968 de Vitanolid D (Withanolide D) (3) isimli antitumoral steroidal laktonların izolasyonu, $W$. somnifera'nm tıbbi etkinliğini kanıtlamıştır.

W. somnifera'nın taşıdı̆̆ 1 steroidal laktonlar bitkinin yetiştiği yerlere göre farklar göstermektedir. İsrail (3), Hindistan (1, 4), Güney Afrika (5) kaynaklı numunelerle yapılan araştırmalar sonucu çeşitli kimyasal ırklar saptanmıştır. Bazı ırklar yalnız Vitaferin A'yı, bazıları Vitanolid D'yi, bazıları ikisini birlikte içermektedir.

$\mathrm{Bu}$ çalışmanın amacı ülkemizde yetişen $W$. somnifera'nın hangi kimyasal ırka girdiğini, genellikle "Vitanolid" diye isimlendirilen antitumoral steroidal laktonları içerip içermediğini saptamaktır.

\section{MATERYAL VE YÖNTEM}

Bitki materyali: $W$ - somnifera ülkemizde Ege ve Akdeniz bölgelerinde yetişmektedir. Araştırmamızda her iki yörede doğal olarak yetişen, ve Ankara'da kültüre alınmış bitkilerin yapraklarıyla çalışıldı. Doğal örnekler İzmir ve İskenderun yakınlarından toplanmış, kültür örneği İzmir kaynaklı bitki tohumundan Ankara'da yetiştirilmişti. Yapraklar havada ve gölgede kurutulduktan sonra kullanıldı.

Redaksiyona verildiği tarih: 15 Aralık 1980

* Farmakognozi ve Farmasötik Botanik Kürsüsü, Eczacılı Fakültesi, Ankara Üniversitesi 
Yöntem: Numunelerden YARDEN ve LAVIE'ye (6) göre hazırlanan alkaloitsiz steroit ekstreleri tanık maddelerle ince tabaka kromatografisine uyguland. Steroidal bileşikler kolon kromatografisi ile ayrıldı ve E. N., tanık maddeyle kromatografik karşıllaştırma, IR spektrumlarının tanık madde IR'larıyla çakışmasıyla tanındı.

\section{BULGULAR}

Hem İzmir, hem İskenderun kaynaklı, hem de kültür numunesinin alkaloitsiz ekstrelerinde ince tabaka kromatografisi ile altı adet steroit lekesi saptand1; lekeler 1-6 olarak numaraland1. Lekelerden iki tanesi Vitaferin A ve Vitanolid D ile çakışmaktaydı (Krom. 1). Kültür numunesinde Vitaferin A ve Vitanolid D dışındaki lekeler küçülmüş, iki steroidal lakton lekesi değişime uğramamıştı.

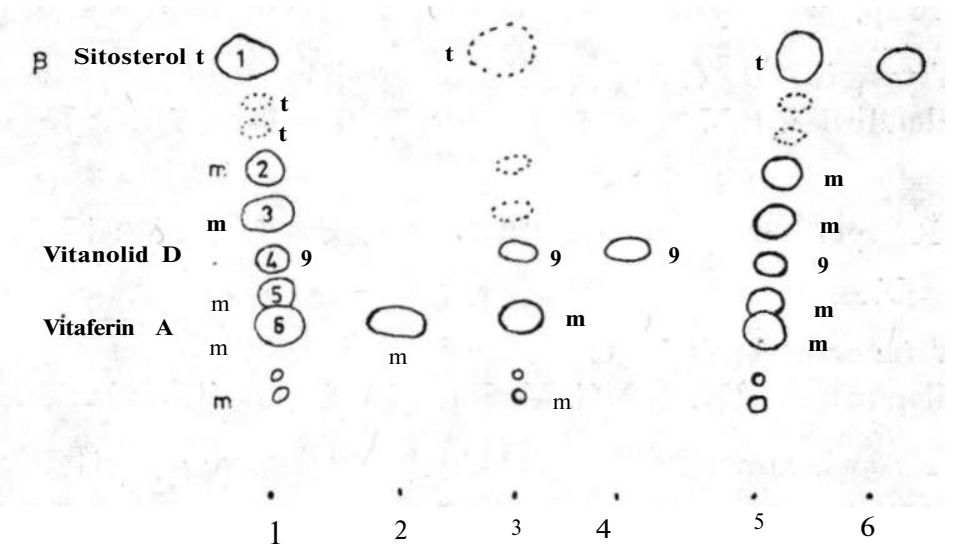

Krom. 1. Doğal kaynaklı W. somnifera yaprak ekstrelerinin ve kültür numunesinin Vitanolidler ve diğer Steroidal bileşikler yönünden incelenmesi.

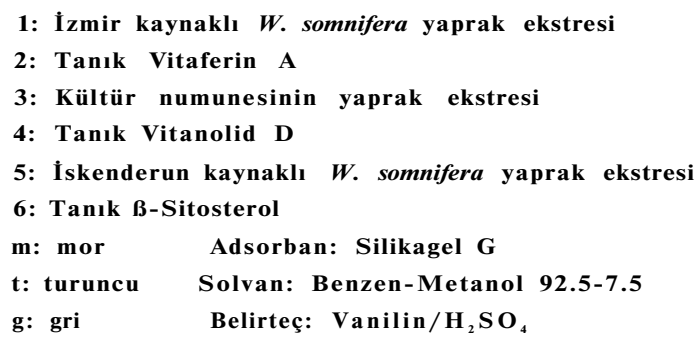


Ekstreler, Kieselgel kolonda benzen-etil asetat karışımıyla elue edildi (Tablo I). Üç adet saf bileşik elde edildi. Bunlar B-sitosterol, Vitaferin A ve Vitanolid D olarak saptandi.

Tablo I: W. somnifera yaprak ekstresinin kolonda ayrılması

\begin{tabular}{|c|c|c|}
\hline Fraksiyon No & Solvan & Bileşik No \\
\hline $\mathbf{1}-\mathbf{5}$ & Benzen-Etil asetat & $\mathbf{1}$ (B-sitosterol) \\
$16-30$ & $\mathbf{8 . 5} \quad \mathbf{1 . 5}$ & 2 ve 3 \\
$31-70$ & $\mathbf{7 . 5} \quad \mathbf{2 . 5}$ & 4 (Vitanolid D) \\
$70-82$ & $" n$ & 4 ve 5 \\
$113-133$ & & 6 (Vitaferin A) \\
\hline
\end{tabular}

P- sitosterol, $\mathrm{C}_{29} \mathrm{H}_{50} \mathrm{O}$ : Kloroform-metanol karışımında kristallendirildi. E.N.: $140^{\circ} \mathrm{C}(\mathrm{C}: 83.55, \mathrm{H}: 12.27 \%)$. Verim: \% 0.7 Olumlu Lieberman reaksiyonu.

IR spektrum $\left(\mathrm{cm}^{-1}\right)=3400(-\mathrm{OH}) ; 2400-3000$ (alifatik zincir)

Vitanolid D, $\mathrm{C}_{28} \mathrm{H}_{56} \mathrm{O}_{6}$ : Petrol eteriyle doyurulmuş asetonda kristallendirildi. E.N.: $249^{\circ} \mathrm{C}$. Verim: \% $0.2(\mathrm{C}=71.32 ; \mathrm{H}=8.25$ $\%) \cdot$

IR spektrum $\left(\mathrm{cm}^{-1}\right): 3420 \quad(-\mathrm{OH}) ; 2920\left(\mathrm{~J}_{\mathrm{C}} \mathrm{H}\right) ; 1690$ $(>\mathrm{C}=0)$.

Vitaferin A, $\mathrm{C}_{28} \mathrm{H}_{56} \mathrm{O}_{6}$ : Petrol eteriyle doyurulmuş asetonda kristallendirildi. E.N. $239^{\circ}$ C. Verim: \% 0.5. (C: 71.46; H: $8.33 \%$ ).

IR spektrum $\left(\mathrm{cm}^{-1}\right)=3420(-\mathrm{OH}) ; 2900(-\mathrm{C}-\mathrm{H}) ; 1695$ $(>\mathrm{C}=0)$.

\section{DENEL KISIM}

Ekstraksiyon: YARDEN ve LAVIE'ye göre yapıldı (6).

Kolon kromatografisi: Ekstre Kieselgel 60 (Merck) ile hazırlanmış 30 X $2.5 \mathrm{~cm}$ boyutlarındaki kolonda Benzen-Etil asetat karışımlarıyla elue edildi. $100 \mathrm{ml}$ lik fraksiyonlar toplandi.

İnce tabaka kromatografisi: Silikagel G plakları ve Benzen-Metanol (92.5-7.5); Kloroform-Aseton (95-5); Siklohekzan-Aseton (6050) solvanları kullanıld1. Lekeler, vanillin $/ \mathrm{H}_{2} \mathrm{SO}_{4}$ ve $\mathrm{SbCl}_{3}$ belir- 
teçleriyle (7) görünür hale geçirildi. Vitanolidler mor-gri, B-sitosterol turuncu renk veriyordu.

IR spektrumları Pye Unicam Sp 1100 Spektrofotometresinde $\mathrm{KBr}$ içinde çekildi.

\section{ÖZET}

İzmir ve İskenderun yörelerinde doğal olarak yetişen Withania somnifera nın yaprakları aynı steroidal bileşikleri içermekte ve bitkiler aynı kimyasal 1rka girmektedir. $\mathrm{Bu}$ 1rk, $W$. somnifera'dan bugüne dek izole edilerek antitumoral (1) etkisi kanıtlanmış her iki steroidal laktonu, yani Vitaferin A ve Vitanolid D'yi taşımaktadır. Major bileşik Vitaferin A'dır. Bu çalışmada Vitaferin A ve Vitanolid D'numunelerden izole edilerek tanınmışlardır. Ayrıca yapraklardan ß-sitosterol de izole edilmiştir.

İzmir Kaynaklı bitki tohumlarından Ankara'da yapılan bir ön kültür denemesi, iklim koşullarının diğer steroidal bileşik miktarlarında bir azalmaya neden olsa bile antitumoral bileşiklerde (Vitaferin A ve Vitanolid D) değişime yol açmadı̆̆ını, W. somnifera'nın Orta Anadolu'da kültüre alınabileceğini ortaya koymuştur.

\section{S UMMARY}

Steroidal compounds of Withania somnifera leaves (Solanaceae) of Turkish origin were investigated, and the specimens were found to belong to a chemotype containing both antitumoral steroidal lactones, Withaferin A, and Withanolid D. Withaferin A is the major constituent. The said compounds and $B$ - Sitosterol were isolated and identified.

A preliminary cultivation attempt produced no variation in the TLC spots of the antitumoral lactones but the other steroid spots in the extracts of the cultivation product diminished.

\section{T E Ş E K K Ü R}

Tanık vitanolidleri sağlıyan Dr. I. Kirson ve Dr. S.K. Chakraborti'ye, bitkilerin toplanmasında emeği geçen Prof. Dr. Mekin Tanker'e teşekkürlerimizi sunar, Prof. Dr. Mustafa Güley'in anısını saygiyla anariz. 


\section{KAYNAKLAR}

1 - Chakroborti, S. K., Banın, K. De, Bandyopadyay, T., Experientia, 30/8, 852, (1974)

2- Shohat, B., Gitter, S., Abraham, A., Lavie, D., CancerChemother. Rep., 51, 271, (1967)

3- Abraham, A., Kirson, I., Glotter, E., Lavie, D., Phytochemistry, 7, 957, (1968).

4 - Kirson, I., Glotter, E., Lavie, D., Abraham, A., J. Chem. Soc (c), 1971, 2032 (1971).

5- Kirson, I., Glotter, E., Abraham, A., Lavie, D., Tetrahedron, 26, 2209 (1970).

6- Yarden, A., Lavie, D., J. Chem. Soc, 1962, 2925 (1962)

7- Stahl, E., Thin Layer Chromatography, George Allen and Umvin Ltd., London, Springer. Verlag, Berlin-Heidelberg. New York (1969) 